\title{
Differences in the Properties of Ionotropic Glutamate Synaptic Currents in Oxytocin and Vasopressin Neuroendocrine Neurons
}

\author{
Javier E. Stern, Mario Galarreta, Robert C. Foehring, Shaul Hestrin, and William E. Armstrong \\ Department of Anatomy and Neurobiology, College of Medicine, University of Tennessee, Memphis, Tennessee 38163
}

\begin{abstract}
Oxytocin (OT) and vasopressin (VP) hormone release from neurohypophysial terminals is controlled by the firing pattern of neurosecretory cells located in the hypothalamic supraoptic (SON) and paraventricular nuclei. Although glutamate is a key modulator of the electrical activity of both OT and VP neurons, a differential contribution of AMPA receptors (AMPARs) and NMDA receptors (NMDARs) has been proposed to mediate glutamatergic influences on these neurons. In the present study we examined the distribution and functional properties of synaptic currents mediated by AMPARs and NMDARs in immunoidentified SON neurons. Our results suggest that the properties of AMPA-mediated currents in SON neurons are controlled in a cell type-specific manner. OT neurons displayed AMPA-mediated miniature EPSCs (mEPSCs) with larger amplitude and faster decay kinetics than VP neurons. Furthermore, a
\end{abstract}

Glutamate is the main excitatory transmitter involved in the control of endocrine function in the hypothalamus (van den Pol et al., 1990). Oxytocin (OT) and vasopressin (VP) neurosecretory cells located in the supraoptic (SON) and paraventricular (PVN) nuclei receive a dense glutamatergic innervation, which accounts for approximately one-fourth of the total number of synaptic contacts to these neurons (van den Pol et al., 1990; Meeker et al., 1993). Furthermore, it is well documented that SON neurons express synaptic AMPA (Gribkoff and Dudek, 1990; Wuarin and Dudek, 1993) and NMDA (Gribkoff, 1991; Yang et al., 1995) receptor subtypes.

Hormone release from neurohypophysial terminals is regulated by the electrical activity of OT and VP neurons and is under a strong glutamatergic influence. During lactation, OT neurons display a periodic bursting activity synchronized among the whole population of neurons, resulting in a pulsatile release of the hormone into the circulation (Wakerley and Lincoln, 1973). In vivo studies have shown that this bursting activity is regulated by NMDA receptors (NMDARs) (Moos et al., 1997) and that OT release during lactation is heavily dependent on activation of AMPA receptors (AMPARs) (Parker and Crowley, 1993). The electrical activity of VP neurons is characterized by an unsynchronized phasic activity in response to hyperosmotic or hypovolemic stimuli (Poulain and Wakerley, 1982), which is also modulated by NMDAR activation (Nissen et al., 1994; Moos et

Received Jan. 11, 1999; accepted Feb. 17, 1999.

The research was supported by National Institutes of Health Grants HD-32152 (W.E.A.), NEI-EY09120 (S.H.), and NS-33579 (R.C.F.). We thank Ms. Inga Warr for technical assistance and Drs. H. Gainer and A. Robinson for providing antibodies.

Correspondence should be addressed to Dr. Javier E. Stern, Department of Pharmacology and Toxicology, School of Medicine, Wright State University, P.O. Box 927, Dayton, OH 45401.

Copyright (C) 1999 Society for Neuroscience $\quad 0270-6474 / 99 / 193367-09 \$ 05.00 / 0$ peak-scaled nonstationary noise analysis of mEPSCs revealed a larger estimated single-channel conductance of AMPARs expressed in OT neurons. High-frequency summation of AMPAmediated excitatory postsynaptic potentials was smaller in OT neurons. In both cell types, AMPA-mediated synaptic currents showed inward rectification, which was more pronounced in OT neurons, and displayed $\mathrm{Ca}^{2+}$ permeability. On the other hand, NMDA-mediated mEPSCs of both cell types had similar amplitude and kinetic properties. The cell type-specific expression of functionally different AMPARs can contribute to the adoption of different firing patterns by these neuroendocrine neurons in response to physiological stimuli.

Key words: oxytocin; vasopressin; hypothalamus; synaptic transmission; AMPA receptors; NMDA receptors al., 1997). In vitro studies have further demonstrated that NMDAR activation induced rhythmic bursting activity in all SON neurons tested (Hu and Bourque, 1992).

Although these data indicate that glutamate plays a key role in regulating the electrical activity of both OT and VP cells, some studies suggest that the two cell subtypes differ in their complement of glutamate receptors. For example, in vivo local application of NMDA agonists in the SON of male rats strongly activated putative VP but not OT neurons (Nissen et al., 1994, 1995). Furthermore, electrical stimulation of the organum vasculosum of the lamina terminalis evoked a strong NMDA component in the evoked EPSPs in VP but not OT neurons (Yang et al., 1994). Recent work by Richardson and Wakerley (1997) also suggests a differential involvement of AMPARs and NMDARs in the activation of OT and VP neurons during glutamatergic stimulation.

To determine whether the differential contribution of glutamate in shaping the activity of SON neurons is caused by the presence of cell type-specific differences in the properties of AMPA- and NMDA-mediated synaptic activity, we examined the distribution and functional properties of synaptic currents mediated by AMPARs and NMDARs in SON neurons. We found that OT and VP neurons display AMPA-mediated synaptic currents with distinct amplitude, kinetic, and voltage-dependent properties, but they exhibit similarly behaving NMDA synaptic currents. Furthermore, AMPARs in both neurons displayed calcium permeability, suggestive of a low expression of the gluR2 receptor subunit. Finally, we observed that AMPARs and NMDARs were colocalized in the majority of synaptic sites.

\section{MATERIALS AND METHODS}

\section{Hypothalamic slices}

Coronal hypothalamic slices (350 $\mu \mathrm{m}$ thick) containing the SON were obtained from 21- to 60-d-old female rats (Holtzman, Harlan) with a 
vibroslicer (D.S.K. Microslicer, Ted Pella, Redding, CA). Ice-cold standard solution was used during slicing (see Solutions below). After sectioning, the slices were placed in a holding chamber containing standard solution at $32-34^{\circ} \mathrm{C}$ for $60 \mathrm{~min}$ and then stored at room temperature until they were used. After an incubation period of at least $1 \mathrm{hr}$, slices were transferred to a submersion-type recording chamber kept at room temperature $\left(22-24^{\circ} \mathrm{C}\right)$. Solutions bathing the slices were bubbled continuously with a gas mixture of $95 \% \mathrm{O}_{2} / 5 \% \mathrm{CO}_{2}(\sim 2 \mathrm{ml} / \mathrm{min})$

\section{Dissociated cells}

SON neurons were acutely dissociated as described previously (Foehring and Armstrong, 1996). Briefly, a thin horizontal strip of the ventral hypothalamus including the optic chiasm/tract and adjacent SON was dissected with the use of iris scissors and placed into oxygenated Hank's buffer solution for $1 \mathrm{hr}$ (see Solutions below). The strip was further reduced by removing midline structures and placed in Hank's solution that contained enzyme (Sigma protease type XIV, $1.0 \mathrm{mg} / \mathrm{ml}$ at $35^{\circ} \mathrm{C}$ ) for 25-30 min. The tissue was washed three times in low-Ca ${ }^{2+}$ Hank's solution $\left(0.1 \mathrm{mM} \mathrm{CaCl}_{2}, 4 \mathrm{mM} \mathrm{MgCl}_{2}\right)$ without enzyme and then triturated with fire-polished Pasteur pipettes three times with successively smaller diameter pipettes. The supernatant was collected after each trituration and transferred to a recording chamber held on an inverted microscope stage. The cells were allowed to settle, and a background flow of HBSS $(\sim 1 \mathrm{ml} / \mathrm{min})$ was established. Magnocellular SON neurons were selected based on the large axis diameter exceeding $20 \mu \mathrm{m}$ (Oliet and Bourque, 1992).

\section{Recording and data analysis}

Hypothalamic slices. Patch pipettes (3-5 M $\Omega$ ) were pulled from thin-wall (1.5 mm outer diameter, $1.17 \mathrm{~mm}$ inner diameter) borosilicate glass (GC150T-7.5, Clark, Reading, UK) on a horizontal electrode puller (P-87, Sutter Instruments, Novato, CA). Whole-cell recordings from SON neurons were made under visual control with an upright microscope (Axioscop, Zeiss, Oberkochen, Germany) equipped with Nomarski infrared-differential interference contrast optics and a water immersion lens $(40 \times)$. SON neurons were initially identified according to their morphological appearance and the presence of a strong transient outward rectification (Bourque, 1988) in response to intracellular current injection (see Fig. 1). In addition, a subset of 45 neurons was filled with biocytin (Horikawa and Armstrong, 1988) and immunoidentified as either OT or VP neurons (see Immunocytochemistry below and also see Fig. 1).

Whole-cell and outside-out patch recordings in voltage-clamp mode (Hamill et al., 1981) were obtained with an Axopatch 200A (Axon Instruments, Foster City, CA) patch-clamp amplifier, and current-clamp recordings were obtained with an EPC-7 (List, Darmstadt, Germany) patch-clamp amplifier. No correction was made for the pipette liquid junction potential (measured to be $+10 \mathrm{mV}$ ). The current output was filtered at $2 \mathrm{kHz}$ and digitized at 16-bit resolution (National Instruments, Austin, TX). The series resistance at the onset of the recordings was on average $11.7 \pm 0.8 \mathrm{M} \Omega$ and was monitored throughout the experiment. Traces were stored on a video recorder device (Vetter, Rebersburg, PA). Data were digitized off-line at 10 or $20 \mathrm{kHz}$ and transferred to a PC. The analysis was restricted to miniature EPSCs (mEPSCs) with fast rise times (measured from 20 to $80 \%$ of the amplitude) of $\leq 0.4 \mathrm{msec}$ for AMPA mEPSCs and $\leq 15 \mathrm{msec}$ for NMDA mEPSCs, which are less likely to be attenuated by dendritic filtering. The detection threshold was set to $-8 \mathrm{pA}$ for AMPA and NMDA mEPSCs. Individual mEPSCs were aligned at the $50 \%$ crossing of the rising phase before averaging. Curve fitting for averaged mEPSCs and patch currents was performed with a single exponential equation. Neuronal input resistance was calculated from the current evoked by a $-10 \mathrm{mV}$ pulse from a holding potential of $-60 \mathrm{mV}$. Membrane time constant was estimated using exponential fits of the voltage transient generated from a short $(5 \mathrm{msec})$ current pulse sufficient to hyperpolarize the membrane by $10-15 \mathrm{mV}$.

Extracellular electrical stimulation using monophasic pulses was applied to the region dorsolateral to the SON (Gribkoff and Dudek, 1990) using a bipolar electrode made from two tightly wound tungsten wires (tip diameter: 1-2 $\mu \mathrm{m}$ ). Current amplitude was set initially to reach threshold for evoked EPSPs and then increased until EPSPs were evoked with each stimulus $(100-350 \mu \mathrm{A}, 0.1 \mathrm{msec})$. To quantify the degree of rectification of extracellularly evoked AMPA EPSCs obtained at different membrane potentials, the rectification index was calculated. It was defined as the ratio of the conductance of the AMPA component measured at $+40 \mathrm{mV}$ divided by the conductance measured at $-70 \mathrm{mV}$.
Solutions. The standard solution contained (in $\mathrm{mm}$ ): $126 \mathrm{NaCl}, 2.5$ $\mathrm{KCl}, 1.25 \mathrm{KH}_{2} \mathrm{PO}_{4}, 1 \mathrm{MgSO}_{4}, 2 \mathrm{CaCl}_{2}, 26 \mathrm{NaCO}_{3}, 20$ glucose, and 0.4 ascorbic acid, pH 7.4 (315-320 mOsm). mEPSC recordings were made in the presence of tetrodotoxin (TTX) $(0.5 \mu \mathrm{M}$; Sigma, St. Louis, MO) and the $\mathrm{GABA}_{\mathrm{A}}$ receptor antagonist bicuculline methiodide $(20 \mu \mathrm{M} ; \mathrm{RBI}$, Natick, MA). Glycine $(10 \mu \mathrm{M})$ was added during recordings of NMDA currents. 1,2,3,4-Tetrahydro-6-nitro-2,3-dioxo-benzo[f]quinoxaline-7sulfonamide disodium (NBQX) and ( \pm )-2-amino-5-phosphonovaleric acid ( \pm APV) were purchased from RBI.

The pipette internal solution contained (in $\mathrm{mM}$ ): $100 \mathrm{D}$-gluconic acid, $100 \mathrm{CsOH}, 20 \mathrm{KCl}, 10 \mathrm{HEPES}, 4 \mathrm{MgATP}, 20$ phosphocreatine (Na), 0.3 NaGTP, 10 EGTA, and 0.050 spermine, pH 7.3, (295 mOsm). For labeling neurons, biocytin $(0.2 \%)$ was added to the pipette internal solution.

Dissociated cells. Whole-cell recordings were obtained at room temperature with a Dagan 8900 amplifier. Electrodes were pulled from Corning 7052 glass (1-2 $\mu \mathrm{m}$ tip) on a Brown-Flaming puller (Sutter) and fired-polished. Electrode resistances were 3-5 M $\Omega$. After attaining a $>1$ G $\Omega$ seal and entering whole-cell mode, electrometer circuitry was used to compensate for $60-80 \%$ of the series resistance. The liquid junction potential $(+10 \mathrm{mV})$ was not corrected. Pulses of kainate $(1 \mathrm{mM}, 5 \mathrm{sec})$ were applied using a low- $\mathrm{Na}^{+}$, high-Ca ${ }^{2+}$ external solution (see Solutions below). By holding the membrane potential at varying voltages, the reversal potential of the kainate-evoked current was obtained. The permeability ratio of $\mathrm{Ca}^{2+}$ versus $\mathrm{Cs}^{+}$using a single $\mathrm{Ca}^{2+}$ concentration was calculated from a variation of the Goldman-Hodgkin-Katz constant

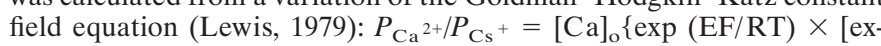
$\mathrm{p}(\mathrm{EF} / \mathrm{RT})+1]\}$.

Data acquisition and analysis were performed with pCLAMP and AXOGRAPH software (Axon Instruments).

Solutions. Hank's solution contained (in mM): 10 HEPES, $138 \mathrm{NaCl}, 3$ $\mathrm{KCl}, 1 \mathrm{MgCl}_{2}, 2 \mathrm{CaCl}_{2}$, and 20 glucose, $\mathrm{pH} 7.3,300 \mathrm{mOsm}$. Kainate currents were evoked using an external solution containing TTX $(0.5$ $\mu \mathrm{M}$ ), in which $\mathrm{NaCl}$ was replaced by an equiosmolar amount of $\mathrm{N}$-methylD-glucamine, and the concentration of $\mathrm{CaCl}_{2}$ was increased to $30 \mathrm{~mm}$. The internal solution consisted of (in $\mathrm{mM}$ ): $100 \mathrm{D}$-gluconic acid, 100 CsOH, $4 \mathrm{MgCl}_{2}$, 40 HEPES, 10 EGTA, 12 phosphocreatine, 0.1 leupeptin, 0.025 spermine, 0.4 GTP, and 2 ATP, pH 7.2, 260-280 mOsm.

Peak-scaled nonstationary noise analysis of fluctuation. To estimate the average single-channel conductance underlying mEPSCs, a nonstationary fluctuation analysis was made as described elsewhere (Traynelis et al., 1993; Silver et al., 1996). Peak-scaled nonstationary noise analysis of fluctuation analysis differs from the conventional form (Sigworth, 1980) in that the averaged mEPSC waveform is scaled to the peak of each mEPSC and then subtracted. Because of the variability in mEPSC size, the open probability and total channel number cannot be estimated, but the mean single-channel current for the mEPSCs can be obtained. For this purpose, a subset of mEPSCs was digitized at $50 \mathrm{kHz}$ from a sample of OT and VP neurons (from 30 to 160 mEPSCs per cell). Because the technique assumes the decay time courses to be similar, mEPSCs were selected with amplitudes of $20-30 \mathrm{pA}$ so that their decay time constants could be measured accurately. In addition, no correlation was observed between the rise time and decay time constant of measured mEPSCs. Those few mEPSCs with time constants outside two times the SD of the normally distributed population were discarded. The difference between the scaled mean and single EPSC waveforms resulted in difference currents with a variance that was higher than background levels. Variance-amplitude relationships for the decay of mEPSCs were plotted, and nonparabolic relationships similar to those described by Traynelis et al. (1993) were obtained (see Fig. 4). The linear part of the plot covering three times the time constant of the averaged mEPSC decay, back calculated from the time of the averaged peak, was fit with a linear regression. The slope of the variance-amplitude relationship was considered as a weighted mean single-channel current and was divided by the driving force, assumed to be $-70 \mathrm{mV}\left(E_{\mathrm{rev}}\right.$ AMPA $=0 \mathrm{mV} ; V_{\mathrm{h}}=-70$ $\mathrm{mV})$, to obtain the average single-channel conductance. As an internal control, we also fitted the initial 35 and $55 \%$ of the current-variance relationship, obtaining similar mean single-channel values (data not shown) (also see Traynelis et al., 1993).

\section{Rapid application to outside-out patches}

Rapid application of glutamate $(10 \mathrm{~mm}, 100 \mathrm{msec})$ to outside-out membrane patches was performed with a piezoelectric element that displaced a pipette made from theta tubing, as described previously (Hestrin, 1992). Rapid solution exchange at the outside-out membrane patch was 

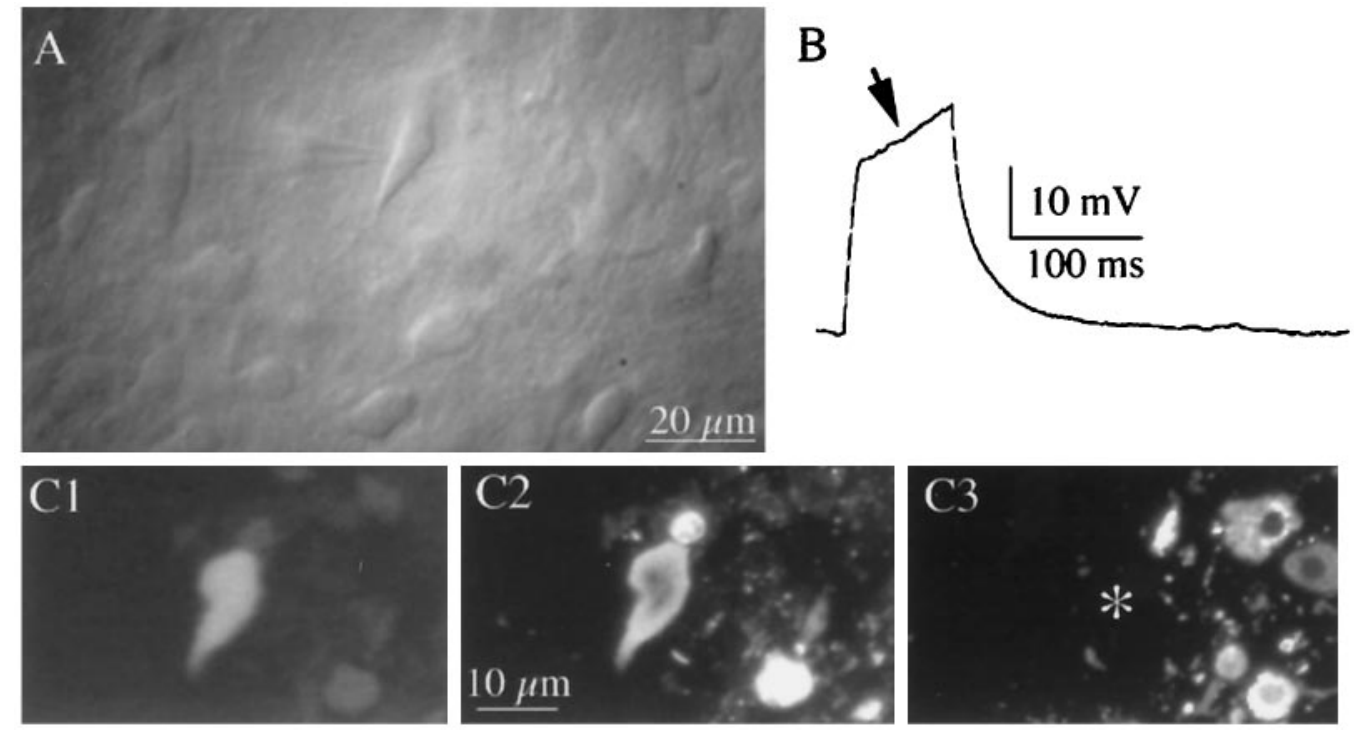

Figure 1. Identification of OT and VP neurons recorded from hypothalamic slices. $A$, Photomicrograph of a SON neuron visualized with infrareddifferential interference contrast videomicroscopy. Note the recording pipette attached to the neuron. $B$, The presence of a strong transient outward rectification (arrow) to depolarizing current injection $(50 \mathrm{pA})$ is characteristic of magnocellular neurons. $C$, Example of an immunochemically identified VP neuron. The neuron was filled with biocytin and immunochemically labeled for VP- and OT-neurophysin by double immunofluorescence. In C1, The recorded neuron is visualized with amino-methylcoumarin-conjugated avidin. $C 2$, The recorded neuron is positively labeled with VP-neurophysin immunoreactivity visualized by fluorescein-conjugated secondary antibody. C3, OT-neurophysin immunoreactivity visualized by tetramethylrhodamineconjugated secondary antibody. The recorded neuron $\left({ }^{*}\right)$ was negative.

obtained by positioning the tip of the patch pipette in the control solution stream near the interface with the glutamate-containing solution stream. In each patch experiment, a series of glutamate pulses was applied to obtain an average current. To measure the pulse duration, the membrane patch was blown away from the tip of the pipette at the end of each experiment. The current generated by the liquid junction potential caused by the $10 \%$ dilution between the control and the glutamatecontaining solution was recorded. The solution exchanged with a rising/ falling time $(20-80 \%)$ of $150 \mu$ sec.

The control solution used for the rapid application system contained (in mM): $135 \mathrm{NaCl}, 0.5 \mathrm{CaCl}_{2}, 1 \mathrm{MgSO}_{4}, 10$ HEPES, and 40 sucrose, $\mathrm{pH}$ $7.3,320 \mathrm{mOsm}$. The glutamate-containing solution was diluted by $10 \%$ with respect to the control one.

\section{Immunohistochemistry}

Double-labeling recorded neurons. After the experiment, slices were fixed in $4 \%$ paraformaldehyde and $0.2 \%$ picric acid, dissolved in $0.15 \mathrm{M}$ phosphate buffer, $\mathrm{pH}$ 7.3. Slices were rinsed in PBS and incubated overnight in avidin-amino-methylcoumarin (Vector Labs, Burlingame, CA) diluted 1:1000 in PBS containing $0.5 \%$ Triton X-100. Neurons were immunochemically labeled for VP- or OT-associated neurophysins by double immunofluorescence labeling either directly on the slices or from serial, $2 \mu \mathrm{m}$ plastic sections cut from embedded slices (Smith and Armstrong, 1993; Stern and Armstrong, 1997). VP neurones were identified with a rabbit antiserum specific for VP-neurophysin (provided by Alan Robinson, University of Pittsburgh, Pittsburgh, PA) at a 1:20,000 dilution, and then revealed by a fluorescein-conjugated goat anti-rabbit secondary antibody. OT neurones were labeled with a mouse antibody PS36 (provided by Harold Gainer and Mark Whitnall, National Institutes of Health) specific for OT-neurophysin, at a dilution of 1:1000, and then revealed by a rhodamine-conjugated goat anti-mouse secondary antibody. All antibodies were diluted with PBS containing $0.5 \%$ Triton $\mathrm{X}-100$. Only neurons showing a positive reaction for one peptide and a negative reaction for the other were included.

\section{Statistical analysis}

All data shown represent the mean \pm SEM. Comparisons of mean values between cell types were performed using a Student's $t$ test. A Kolmogorov-Smirnov Test was used to compare the amplitude and frequency distributions between cell types.

\section{RESULTS}

To study the properties of EPSCs of SON neurons, whole-cell patch-clamp recordings were obtained from a total of 75 SON neurons in hypothalamic slices. Of these, 17 were identified as OT-positive and 28 as VP-positive neurons. An example of an immunoidentified VP neuron is shown in Figure 1. Average input resistance and membrane time constant were $1.1 \pm 0.1 \mathrm{G} \Omega$ and $27.2 \pm 4.3 \mathrm{msec}$, respectively. No differences were observed between cell types (results not shown).

\section{Contribution of AMPA and NMDA type receptors to EPSCs in OT and VP neurons}

Evoked EPSCs were obtained by extracellular electrical stimulation dorsolaterally to the SON $(n=8)$ (see Materials and Methods). Neurons were voltage-clamped at varying membrane potentials, and the sensitivity of the evoked currents to different pharmacological agents was tested. In control conditions [artificial CSF (ACSF) $+20 \mu \mathrm{M}$ bicuculline], fast rising and decaying inward currents were observed at membrane potentials more negative than $0 \mathrm{mV}$. At more depolarized membrane potentials, the currents reversed polarity, and fast and slow components were observed (Fig. 2A1). In the presence of NBQX (10 $\mu \mathrm{M})$, an AMPAR antagonist, both inward and outward fast components were blocked (Fig. 2A2), leaving only slowly decaying outward currents that were sensitive to the NMDAR antagonist ( \pm ) APV $(100 \mu \mathrm{M})$ (Fig. 2A2, inset). These features were observed in eight neurons, three of which were identified as VP and two as OT neurons. These results indicate that both AMPA and NMDA type receptors contribute to the evoked EPSCs in OT and VP SON neurons.

To determine whether AMPARs and NMDARs are colocalized at individual synapses in SON neurons, we recorded mEPSCs, which reflect the activation of receptors at a single synaptic site (Redman, 1990). mEPSCs were recorded at -50 

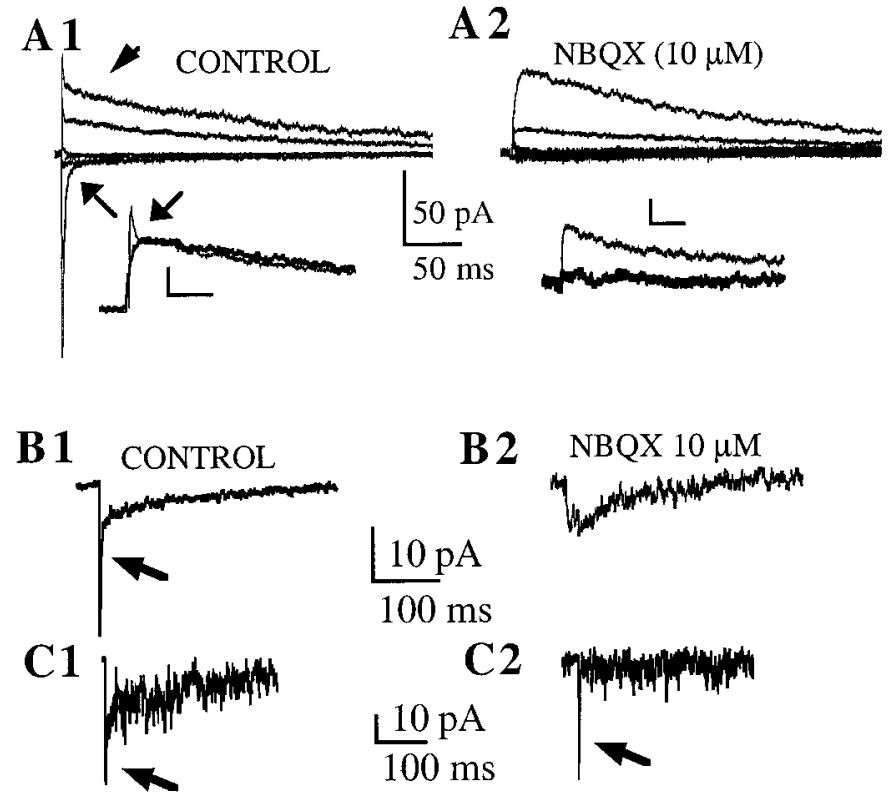

Figure 2. AMPA and NMDA receptors contribute to EPSCs in OT and VP neurons. Colocalization at single synapses. A1, Example of EPSCs in an OT neuron evoked by extracellular electrical stimulation in the dorsolateral area to the SON. A single shock $(150 \mu \mathrm{A})$ evoked synaptic currents with fast and slow components. At membrane potentials below 0 $\mathrm{mV}$, inward currents displayed only fast kinetics (arrow). However, outward currents obtained at more depolarized membrane potentials showed an additional prominent slow component (arrowhead). A2, NBQX (10 $\mu \mathrm{M})$ blocked fast components of evoked synaptic currents, leaving only slowly decaying outward currents. The inset in $A 1$ shows superimposed and expanded outward currents from $A$ and $B$ to show more clearly the effect of NBQX (thick line trace) on the fast outward current (arrow). The inset in $A 2$ shows that the slow outward currents were blocked by \pm APV $(100 \mu \mathrm{M})$ (thick line trace). Calibration in insets: $18 \mathrm{pA}, 25 \mathrm{msec} . B$, Example of mEPSCs recorded in a VP neuron. mEPSCs were recorded at $-50 \mathrm{mV}$ in the presence of $20 \mu \mathrm{M}$ extracellular $\mathrm{Mg}^{2+}$ to optimize the detection of currents mediated by both receptor types. $B 1$ shows averaged mEPSCs $(n=138)$ recorded in this condition, showing both fast (arrow) and slow inward components. B2 shows averaged mEPSCs $(n=25)$ obtained in the presence of NBQX $(10 \mu \mathrm{M})$, showing the blockade of the fast component. $C$, A representative example of a single event recorded from the same neurons as in $B$ is shown in $C 1$, displaying fast (arrow) and slow components. In some cases, events displaying only fast components (arrow) were observed (C2).

$\mathrm{mV}$, in the presence of TTX $(0.5 \mu \mathrm{M})$ and $20 \mu \mathrm{M} \mathrm{Mg}{ }^{2+}$ in the ACSF (three VP neurons, two OT neurons, one not identified). This condition optimizes the detection of currents mediated by both receptor types at the same membrane potential. Figure $2 B, C$ shows an example of a VP neuron. Averaged mEPSCs displayed fast (NBQX-sensitive) and slow ( \pm APV-sensitive) components, indicating that both receptor types were activated (Fig. 2B). Analysis of individual mEPSCs revealed that $60 \pm 6 \%$ of the events displayed clear AMPA and NMDA components, whereas $22 \pm 6 \%$ of the events displayed only the AMPA component (Fig. $2 C$ ). The clear presence of fast and slow components in the $18 \%$ of the remaining cases was hard to establish because of their small amplitude, although a small percentage of them appeared to be pure NMDA events. These results suggest that at least $60 \%$ of proximal excitatory synapses in OT and VP neurons colocalize both AMPARs and NMDARs.

Previous studies have shown that AMPARs and NMDARs play an important role in controlling the electrical activity of OT and VP neurons and the release of their peptides into the circu-
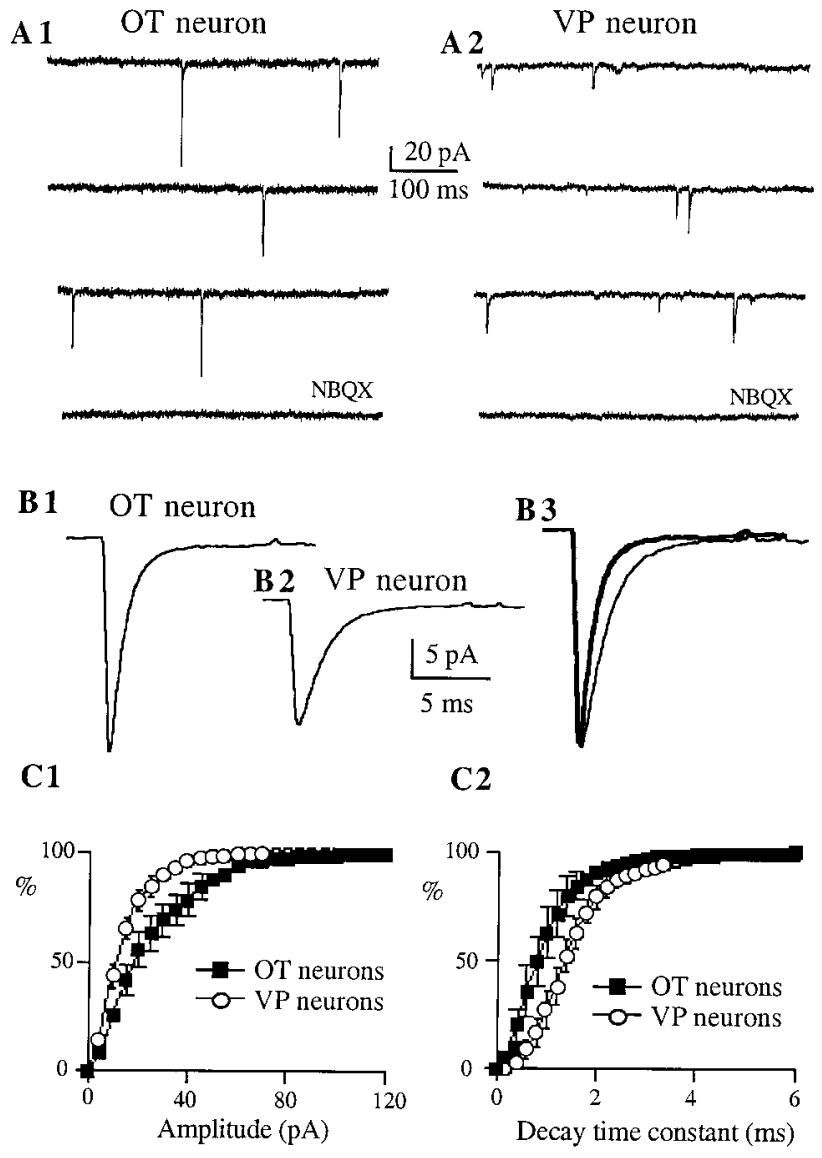

Figure 3. AMPA mEPSCs of OT neurons show larger amplitude and faster decay kinetics as compared with VP neurons. $A$, Representative AMPA mEPSCs obtained from immunoidentified OT $(A 1)$ and VP $(A 2)$ neurons. Synaptic activity was recorded in the presence of bicuculline (20 $\mu \mathrm{M})$ and \pm APV $(100 \mu \mathrm{M})$, at a holding potential of $-70 \mathrm{mV}$. These synaptic events were blocked by NBQX $(10 \mu \mathrm{M})$. B, Average of 317 mEPSCs from the same OT neuron (B1) and average of 486 mEPSCs from the same VP neuron (B2). Note the larger amplitude of the averaged mEPSC obtained in the OT neuron. In $B 3$, both responses were scaled to the same (larger) peak amplitude to facilitate the comparison of their decay times. Note the faster decay kinetics of the averaged mEPSC of the OT neuron (thick line trace). $C$, Averaged cumulative distribution histograms of the amplitude $(C 1)$ and decay time constant (C2) of AMPA mEPSCs obtained from eight OT (squares) and VP (circles) neurons. The amplitude and the decay time constant distributions were significantly different between cell types $(p<0.0001$ in both cases; KolmogorovSmirnov Test).

lation in response to physiological stimuli (for review, see Armstrong, 1995). However, some studies suggest either that OT neurons lack functional NMDA receptors (Nissen et al., 1994, 1995) or that a differential contribution of these receptor subtypes to glutamate excitation exists between the two cell types (Yang et al., 1994; Richardson and Wakerley, 1997). To address this apparent disparity, we studied whether OT and VP neurons express synaptically activated glutamate receptors with different properties.

\section{Comparison of AMPA-mediated synaptic currents in OT and VP neurons}

Figure 3 shows representative examples of AMPA mEPSCs recorded in immunoidentified OT and VP neurons. AMPA mEPSCs were pharmacologically isolated with \pm APV $(100 \mu \mathrm{M})$. To minimize the influence of dendritic filtering in this analysis, 


\begin{tabular}{|c|c|c|c|c|c|}
\hline & $\begin{array}{l}\text { Amplitude } \\
(\mathrm{pA})\end{array}$ & $\begin{array}{l}\text { Frequency } \\
(\mathrm{Hz})\end{array}$ & $\begin{array}{l}\text { Rise time } \\
(\mathrm{msec})\end{array}$ & $\tau(\mathrm{msec})$ & Estimated $g(\mathrm{pS})$ \\
\hline OT neurons & $\begin{array}{l}-27.4 \pm 2.3 \\
(8)\end{array}$ & $\begin{array}{l}0.8 \pm 0.5 \\
(8)\end{array}$ & $\begin{array}{l}0.2 \pm 0.01 \\
(8)\end{array}$ & $\begin{array}{l}0.9 \pm 0.1 \\
(8)\end{array}$ & $\begin{array}{l}29.8 \pm 5.9 \\
(6)\end{array}$ \\
\hline VP neurons & $\begin{array}{l}-19.2 \pm 1.4 \\
(8)^{* *}\end{array}$ & $\begin{array}{l}1.2 \pm 0.2 \\
(8)\end{array}$ & $\begin{array}{l}0.3 \pm 0.01 \\
(8)\end{array}$ & $\begin{array}{l}1.8 \pm 0.2 \\
(8)^{* * *}\end{array}$ & $\begin{array}{l}11.7 \pm 2.2 \\
(7)^{*}\end{array}$ \\
\hline
\end{tabular}

Shown are the means \pm SEM (number of neurons in parentheses). ${ }^{*} p<0.02,{ }^{*} p<<0.01$, and ${ }^{* * *} p<0.001$, as compared with OT neurons (Student's $t$ test). Neurons were voltage-clamped at $-70 \mathrm{mV}$. The average single channel conductance $(g)$ of AMPARs underlying mEPSCs was estimated using a peak-scaled nonstationary noise analysis (see Materials and Methods for details).

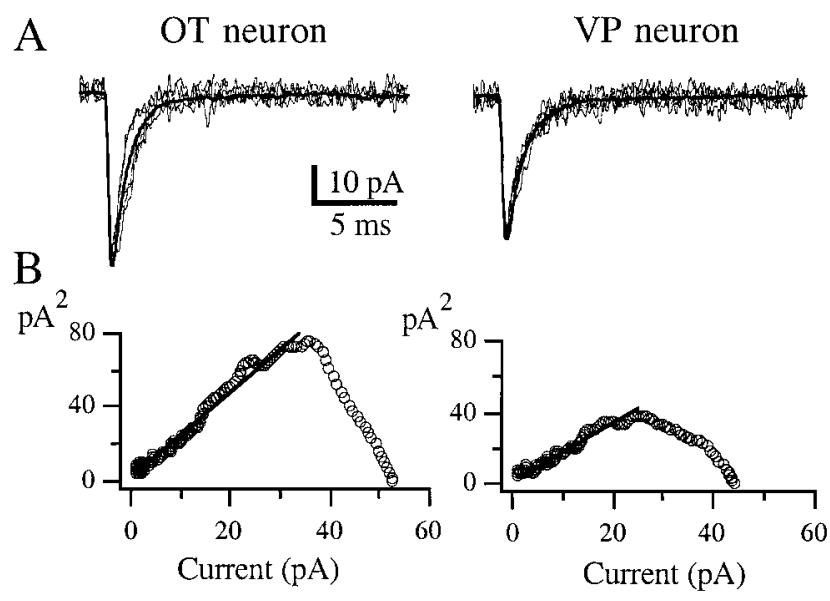

Figure 4. Peak-scaled nonstationary noise analysis of AMPA mEPSCs in SON neurons. $A$, Eight AMPA mEPSCs of similar amplitude are superimposed over the scaled mean mEPSC waveform (smooth curve) for an OT (left panel) and a VP (right panel) neuron. B, Variance-amplitude relationship of the OT (62 mEPSCs) and VP (95 mEPSCs) neuron. The solid line represents a linear regression (see Materials and Methods). The estimated single-channel conductances were 33.7 and $15.7 \mathrm{pS}$ for the OT and VP neurons, respectively (Table 1).

only AMPA mEPSCs with rise times $(20-80 \%) \leq 0.4$ msec were selected. Under these conditions, a multiple correlation analysis indicated that mEPSC amplitude, rise time, and decay time constant were not correlated in either cell-type group $\left(r^{2}\right.$ range: 0.0001-0.06). On average ( $n=8$ for each cell type), mEPSCs recorded from OT neurons showed significantly larger amplitudes $(p<0.01)$ and faster decay time constants $(p<0.001)$ than VP neurons (Table 1). This is also shown as a significant shift in the mean amplitude and decay time constant frequency distribution histograms of AMPA mEPSCs (Fig. 3C1,2) ( $p<0.0001$, Kolmogorov-Smirnov Test). On the other hand, neither rise time $(p>0.1)$, nor the frequency $(p>0.5)$ of mEPSCs varied between cell types (Table 1). As observed at other excitatory synapses in the CNS (Hestrin, 1992), AMPA mEPSCs showed variable peak amplitudes. The mean coefficient of variation $[(\mathrm{CV})$ $\mathrm{SD} /$ mean] of AMPA mEPSCs was similar between cell types (OT neurons: $0.55 \pm 0.03$; VP neurons: $0.54 \pm 0.02 ; p>0.6$ ).

To study the conductance properties of synaptic AMPARs, a peak-scaled nonstationary fluctuation analysis of AMPA mEPSCs was performed, and an estimate of the single-channel conductance was obtained (Traynelis et al., 1993; Silver et al., 1996) (see Materials and Methods). Figure 4 shows examples of variance-amplitude plots obtained from an OT and a VP neuron. In general, nonparabolic relationships were obtained (Traynelis et al., 1993), and the single-channel current was estimated by fitting a linear regression to the variance-amplitude plots over different proportions of the time course of the averaged synaptic decay (see Materials and Methods). Assuming a reversal potential of $0 \mathrm{mV}$, the estimated single-channel conductance of AMPARs obtained from OT neurons was significantly larger than that of VP neurons (Fig. 4, Table 1) $(p<0.02)$.

\section{AMPA receptors in OT and VP neurons display inward rectification and calcium permeability}

Current-voltage $(I-V)$ curves of AMPA mEPSCs were obtained from nine neurons (three VP, three OT, and three not identified), by recording synaptic events at varying membrane potentials. AMPA mEPSCs in both cell types displayed strong inward rectification at holding potentials between 0 and $+40 \mathrm{mV}$ (Fig. 5A). These results were confirmed by studying evoked EPSCs in six OT and six VP neurons (Fig. 5B). To quantify and compare the degree of rectification between cell types, a rectification index was calculated (see Materials and Methods). We found that AMPA-mediated evoked EPSCs in OT neurons displayed a significantly stronger rectification as compared with $\mathrm{VP}$ neurons (OT neurons: $0.23 \pm 0.05$; VP neurons: $0.43 \pm 0.07 ; p<0.04$ ). To exclude the possibility that the rectification of the $I-V$ relationship was caused by dendritic filtering, we studied the properties of AMPARs in unidentified SON neurons using rapid applications of glutamate to excised membrane patches. Figure $5 C$ shows rapid applications of prolonged $(100 \mathrm{msec})$ pulses of glutamate $(10 \mathrm{~mm})$ to outside-out patches in the presence of $\pm \mathrm{APV}$. $I-V$ plots constructed from AMPA currents evoked in excised patches $(n=6)$ exhibited rectification similar to that of synaptic currents (Fig. 5C, bottom panel).

Previous studies with recombinant or native AMPARs demonstrated that inwardly rectifying AMPARs are also characterized by a relatively high calcium permeability (for review, see Burnashev, 1996). To determine whether the inwardly rectifying AMPARs of SON neurons also are calcium permeable, we recorded AMPAR-mediated currents evoked by kainate in an extracellular solution containing $\mathrm{Ca}^{2+}(30 \mathrm{~mm})$ as the only permeant ion. We then calculated the permeability ratio of $\mathrm{Ca}^{2+}$

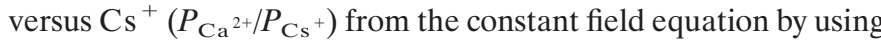
reversal potentials of kainate currents obtained in this condition (see Materials and Methods). Kainate pulses (1 mm, $5 \mathrm{sec}$ ) were applied to the surface of acutely dissociated SON neurons while holding the membrane potential at different values. Nondesensitizing inward and outward currents were observed in response to kainate application (results not shown). Because $\mathrm{Ca}^{2+}$ was the only permeant cation in the external solution, the recorded inward currents had to be carried by $\mathrm{Ca}^{2+}$. From five such experiments, we obtained a mean reversal potential of kainate currents 
Figure 5. AMPA receptors in OT neurons displayed stronger inward rectification. $A$, AMPA mEPSCs recorded at varying membrane potentials in a representative VP (left panel) and OT neuron (right panel). When neurons were voltage-clamped below $0 \mathrm{mV}$, mEPSCs were observed as fast inward currents. However, AMPA mEPSCs were not observed at membrane potentials between 0 and +40 $\mathrm{mV}$, and only reversed at membrane potentials of $+60 \mathrm{mV}$ or above. $B$, AMPA EPSCs were evoked by extracellular stimulation in the presence of bicuculline $(20 \mu \mathrm{M})$ and \pm APV $(100 \mu \mathrm{M})$ while holding the neuron at varying membrane potentials (from -70 $\mathrm{mV}$ to $+40 \mathrm{mV})$. The bottom panel shows averaged $I-V$ curves obtained from six OT ( $\square$ ) and six VP (ם) neurons, displaying a stronger inward rectification in OT neurons. $C$, Responses of outside-out patches excised from SON neurons to a rapid application of glutamate $(10 \mathrm{mM}, 100 \mathrm{msec}$ ) while holding the neuron at varying membrane potentials (from $-70 \mathrm{mV}$ to $+60 \mathrm{mV}$ ). The bottom panel shows an averaged $I-V$ curve obtained from six neurons displaying inward rectification.

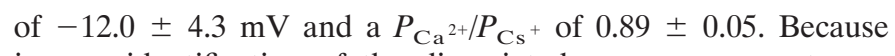
immunoidentification of the dissociated neurons was not routinely possible after whole-cell recordings, we did not compare $\mathrm{Ca}^{2+}$ permeability in OT and VP neurons.

The rectification properties and permeability to divalent ions of AMPARs depend on subunit composition: AMPAR permeability to $\mathrm{Ca}^{2+}$ varies inversely with the relative abundance of gluR2 subunit mRNA (for review, see Burnashev, 1996). Our results then would suggest that AMPARs of SON neurons have low

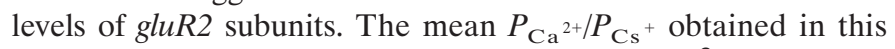
study corresponds to an intermediate degree of $\mathrm{Ca}^{2+}$ permeability (Geiger et al., 1995), consistent with the expression of some functional gluR2-containing receptors.

\section{Comparison of NMDA-mediated synaptic currents in OT and VP neurons}

NMDA mEPSCs were pharmacologically isolated with NBQX $(10 \mu \mathrm{M})$. Figure 6 shows representative examples of NMDA mEPSCs recorded in immunoidentified OT and VP neurons. NMDA mEPSCs were observed in all recorded neurons. However, no significant differences in the properties of these synaptic events were observed as a function of the cell type (Fig. 6, Table 2). Similar to AMPA mEPSCs, NMDA mEPSC s showed variable peak amplitudes. The mean CV was similar between cell types (OT neurons: $0.41 \pm 0.04$; VP neurons: $0.39 \pm 0.02 ; p>0.4$ ). Interestingly, the CV of NMDA mEPSCs was significantly smaller than that of AMPA mEPSCs in both cell types $(p<0.02$ and $p<0.0001$ for OT and VP neurons, respectively).

\section{Summation of AMPA-mediated EPSPs during repetitive stimulation in OT and VP neurons}

To determine whether the differences observed in the properties of AMPA EPSCs between cell types were accompanied by a different ability of SON neurons to integrate high-frequency AMPA-mediated synaptic inputs during repetitive stimulation, we recorded EPSPs (current-clamp mode) evoked by $50 \mathrm{~Hz}$ extracellular electrical stimulation in the presence of $\pm \mathrm{APV}$ while holding the neurons at $-70 \mathrm{mV}$. Figure 7 shows representative EPSPs recorded from an OT and a VP neuron in response to a single shock stimulation. No significant differences in the EPSP amplitude (in millivolts) (OT neurons: $2.6 \pm 0.9$; VP neurons: $3.9 \pm 1.1$ ) or decay time constant (in milliseconds) (OT neurons: $42.9 \pm 6.2$; VP neurons: $53.9 \pm 8.1)$ were observed between cell types ( $p>0.05 ; n=8$ and $n=4$ for VP and OT neurons, respectively). During a $50 \mathrm{~Hz}$ stimulation, EPSPs suc-
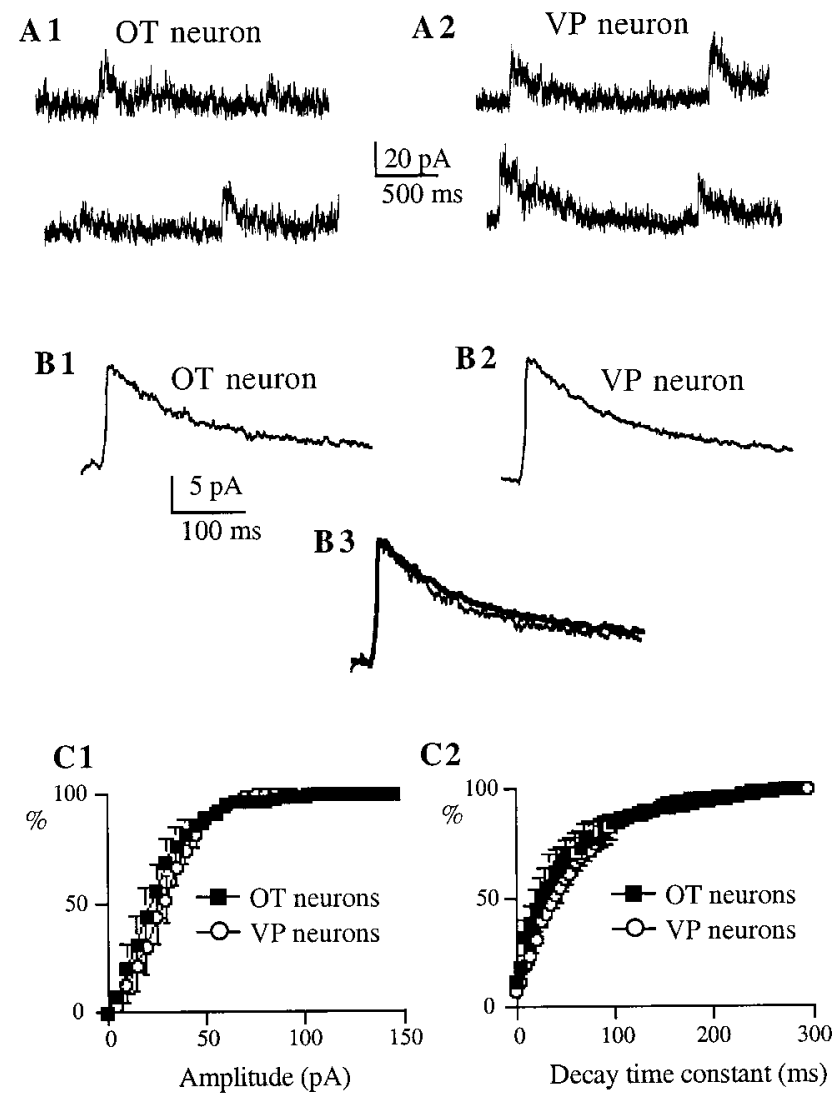

Figure 6. NMDA mEPSCs of OT and VP neurons show similar properties. $A$, Representative NMDA mEPSCs obtained from immunoidentified OT $(A 1)$ and VP $(A 2)$ neurons. Synaptic activity was recorded in the presence of bicuculline $(20 \mu \mathrm{M})$ and $\operatorname{NBQX}(10 \mu \mathrm{M})$, at a holding potential of $+60 \mathrm{mV}$. $B$, Average of $338 \mathrm{mEPSCs}$ from the same VP neuron (B1) and average of 154 mEPSCs from the same OT neuron (B2). In $B 3$, both responses were scaled to the same peak amplitude to facilitate the comparison of their decay times. Neither the amplitude nor the decay rate was different between cell types (VP neuron trace is in thick line). $C$, Averaged cumulative distribution histograms of the amplitude $(C 1)$ and decay time constant $(C 2)$ of NMDA mEPSCs obtained from six OT (squares) and nine VP (circles) neurons, showing similar distributions in both cases $(p>0.05$ in both cases; Kolmogorov-Smirnov Test). 


\begin{tabular}{|c|c|c|c|c|}
\hline & $\begin{array}{l}\text { Amplitude } \\
(\mathrm{pA})\end{array}$ & $\begin{array}{l}\text { Frequency } \\
(\mathrm{Hz})\end{array}$ & $\begin{array}{l}\text { Rise time } \\
(\mathrm{msec})\end{array}$ & $\tau$ (msec) \\
\hline OT neurons & $24.6 \pm 5.5$ & $0.16 \pm 0.50$ & $3.4 \pm 0.4$ & $82.1 \pm 24.3$ \\
\hline VP neurons & $28.1 \pm 3.2$ & $0.17 \pm 0.30$ & $3.3 \pm 0.4$ & $97.3 \pm 14.1$ \\
\hline
\end{tabular}

Shown are the means \pm SEM $(n=6$ and 9 for OT and VP neurons, respectively). Neurons were voltage-clamped at $+60 \mathrm{mV}$, in the presence of $1.2 \mathrm{~mm}$ extracellular $\mathrm{MgCl}_{2}$.
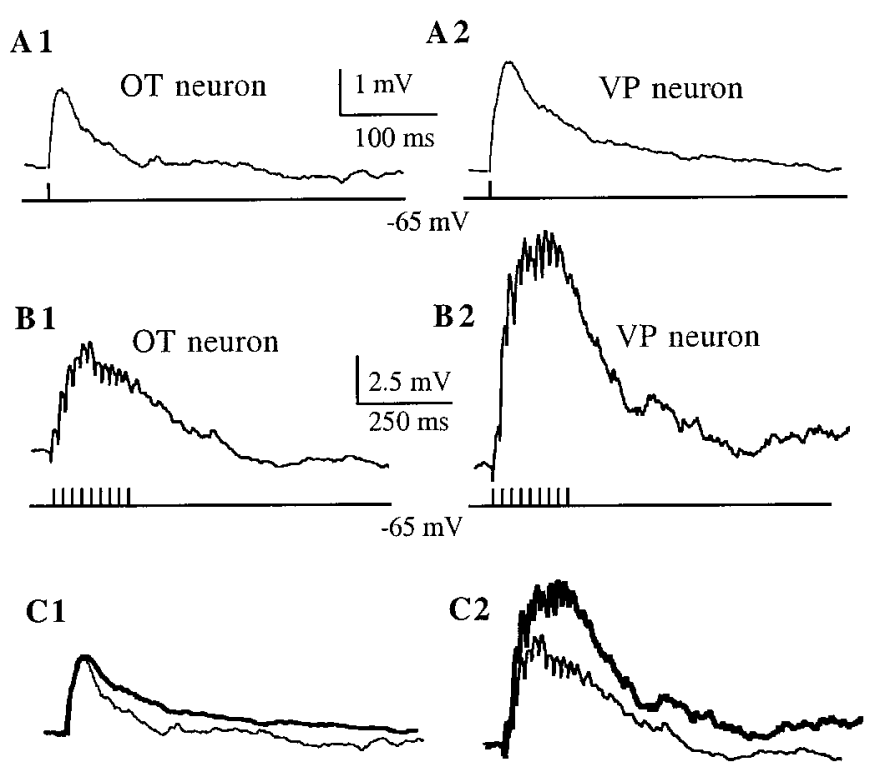

Figure 7. Summation of AMPA-mediated EPSPs during high-frequency synaptic stimulation. EPSPs were evoked by a single- or high-frequency $(50 \mathrm{~Hz}, 200 \mathrm{msec})$ extracellular stimulation dorsolateral to the SON. Neurons were current-clamped at $-70 \mathrm{mV}$. All traces were taken in the presence of \pm APV $(100 \mu \mathrm{M})$. $A$, Averaged EPSP $(n=60)$ obtained in an OT $(A 1)$ and VP $(A 2)$ neuron in response to a single shock stimulus. $B$, During a $50 \mathrm{~Hz}$ stimulation, EPSPs summed to form a slow depolarization that outlasted the duration of the stimulus. Note that the slow depolarization was larger in the VP (B2) than in the OT (B1) neuron. All traces are averages $(n=6)$. $C$, The EPSP in the VP neuron (thick line) was normalized to the amplitude of the EPSP in the OT neuron, and the traces are shown superimposed $(C 1)$. The same scaling factor was then used to scale down the envelope of the VP neuron (thick line), still showing a larger amplitude than the envelope in the OT neuron (C2).

cessively summed, inducing a slow depolarization that outlasted the stimulation period, similar to that described previously by Yang et al. (1994) (Fig. 7B). The slow depolarization was completely blocked by NBQX (10 $\mu \mathrm{M})$ (results not shown). To compare the efficiency of EPSP summation between cell types, the area of the slow depolarization (millivolts $\times$ milliseconds) was normalized to the amplitude of the corresponding EPSP. The normalized area of the slow depolarization was significantly larger in VP than in OT neurons (VP neurons: $1316.5 \pm 170.9$; OT neurons: $643.2 \pm 234.2)(p<0.05 ; n=8$ and $n=4$ for VP and OT neurons, respectively). A weak correlation was observed between the amplitude of the slow depolarizations and EPSP amplitude $\left(r^{2}=0.48\right)$ or EPSP time constant $\left(r^{2}=0.51\right)$.

\section{DISCUSSION}

The main findings of this study can be summarized as follows. First, both OT and VP neurons express synaptic AMPA and
NMDA receptors, which in the majority of the cases are colocalized at single sites. Second, the properties of AMPA- but not NMDA-mediated synaptic currents are different between cell types.

\section{OT and VP neurons express AMPA synaptic currents with different properties}

AMPARs are formed from multimeric assemblies of four different subunits ( gluR1-gluR4). The relative expression of these subunits gives rise to a diversity of combinations that result in the expression of functionally different receptors (Hollman and Heinemann, 1994). Our results suggest that the expression of AMPARs, as revealed by AMPARs and synaptic current properties, is differentially controlled in OT and VP neurons. This is supported by the observation that OT neurons displayed AMPA mEPSCs that were larger and decayed faster than those in VP neurons.

The differences in mEPSCs amplitude could be caused in part by the expression of channels with a different unitary conductance. In fact, our results from the nonstationary variance analysis indicate that the estimated mean single-channel conductance of synaptic AMPARs is larger in OT than in VP neurons. Several studies indicate that conductance and permeation properties of recombinant and native AMPARs depend on their molecular structure, more specifically, on the relative abundance of gluR2 (Geiger et al., 1995, Angulo et al., 1997).

Our results suggest that AMPARs in OT and VP neurons also differ in their channel-gating kinetics. This is supported by the fact that the decay time course of AMPA EPSCs is determined in general by channel deactivation kinetics rather than channel desensitization (Hestrin, 1992, 1993; for review, see Jonas and Spruston, 1994). The identity of the molecular determinants controlling native AMPARs kinetics is still controversial. Although some data suggest a positive correlation between the deactivation and desensitization time constants of AMPARs with the relative abundance of gluR2 mRNA (Geiger et al., 1995), the permeation and kinetic properties of native AMPARs expressed in cortical interneurons can be controlled independently, suggesting that the levels of gluR2 expression may not be the sole determinant of AMPARs kinetics (Angulo et al., 1997).

The cell-type differences we observed in the conductance and kinetic properties of AMPA mEPSCs suggest that these neurons express subtypes of AMPARs with different physiological properties. However, other alternatives should also be considered. First, the differences could be attributable to a dissimilar dendritic filtering. We have shown that OT and VP neurons have distinct dendritic topologies (Stern and Armstrong, 1998) that could generate a differential dendritic filtering. To minimize the influence of dendritic filtering, we have restricted the analysis to fast-rising mEPSCs, where no correlation was observed among mEPSC amplitude, decay time constant, or rise time. Last, a differential modulation of the same receptor should also be considered.

During high-frequency stimulation, evoked EPSPs summed to induce a slow depolarization that was significantly smaller in OT neurons. Although EPSPs in OT neurons tended to decay faster, the weak correlation observed between the decay time constant of EPSPs and the amplitude of the slow depolarizations suggests that the cell-type differences in the synaptic integration of highfrequency inputs can be explained only partially by differences in channel decay kinetics. On the other hand, it has been suggested that channel desensitization could limit the ability of the postsyn- 
aptic neuron to follow high-frequency inputs (Jones and Westbrook, 1996). Thus, it is possible that AMPARs of SON neurons also differ in their degree of desensitization.

\section{AMPARs in SON neurons show inward rectification and high calcium permeability}

Recent data indicate that AMPARs expressed in several neuronal populations have an appreciable permeability to $\mathrm{Ca}^{2+}$ (for review, see Burnashev, 1996). Both rectification properties and divalent ion permeability of AMPARs are inversely correlated with the relative abundance of $g l u R 2$ mRNA (Burnashev, 1996). We found that AMPARs in both SON cell types displayed strong inward rectification, which was more pronounced in OT neurons, and that AMPARs are calcium permeable. Using the reversal potential of kainate responses to estimate the permeability ratio of $\mathrm{Ca}^{2+}$ versus $\mathrm{Cs}^{+}$(Lewis, 1979), we obtained values that would correspond to an intermediate degree of $\mathrm{Ca}^{2+}$ permeability, as compared with those obtained from native AMPARs in other neuronal populations (Geiger et al., 1995). This suggests that AMPARs of SON neurons are assembled with relatively low amounts of gluR2 subunits.

In summary, our studies on the properties of AMPA-mediated currents in OT and VP neurons suggest that these neurons may express functionally different AMPARs, which may arise from a differential combination of receptor subunits and/or their modulation. The differences in estimated single-channel conductance, rectification, and kinetics of AMPA-mediated synaptic currents point to a relative difference in $g l u R 2$ expression as a possible candidate (Hollman and Heinemann, 1994; Geiger et al., 1995; Angulo et al., 1997). Data from quantitative studies of protein and/or mRNA expression will be necessary to confirm this hypothesis.

\section{The properties of NMDA synaptic currents are similar in OT and VP neurons}

Although several studies (for review, see Armstrong, 1995) suggest that NMDARs are present ubiquitously in SON neurons, it also has been postulated that OT neurons may lack NMDARs (Nissen et al., 1994, 1995; Yang et al., 1994) or that a differential contribution of NMDARs to glutamate activation exists between cell types (Richardson and Wakerley, 1997). The NMDA synaptic currents we recorded from OT and VP neurons showed comparable properties, supporting a role for NMDARs in both cell types (Yang et al., 1995, Moos et al., 1997). In general, NMDA synaptic currents were similar to those observed in other neurons (for review, see McBain and Mayer, 1994), although they were characterized by a relatively faster rise time $(\sim 3 \mathrm{msec}$, as compared with $\sim 10 \mathrm{msec}$ observed in other neurons). Our results did not reveal evidence for the presence of functionally diverse synaptic NMDARs in the two SON cell types, indicating that neither a selective presence of these receptors nor differences in their properties underlie their differential contribution to the regulation of the electrical activity of SON neurons. It was reported recently that OT and VP neurons show a different pattern of NMDAR subunit expression, such that a differential sensitivity to $\mathrm{Mg}^{2+}$ blockade could exist (Al-Ghoul et al., 1997). More detailed studies on the $\mathrm{Mg}^{2+}$ sensitivity in identified SON neurons are needed to confirm this issue.

\section{AMPA and NMDA receptors are colocalized at single synaptic sites}

We indirectly demonstrated that AMPARs and NMDARs in OT and VP neurons are colocalized at single synaptic sites by record- ing dual component mEPSCs. Similar to hippocampal excitatory synapses (Bekkers and Stevens, 1989), most (>60\%) mEPSCs in SON neurons showed AMPA and NMDA components, whereas $\sim 20 \%$ of mEPSCs seemed to be pure AMPA currents. The presence of both receptors at a single synaptic site provides the basis for local interactions between GLURs needed for some forms of synaptic plasticity. Furthermore, colocalization of both GLURs in SON neurons could result in a negative modulation of NMDARs during glutamate activation, because of rapid increases in $\mathrm{Ca}^{2+}$ through AMPARs (McBain and Mayer, 1994).

In this study we observed a large variability in the quantal amplitude of mEPSCs. Interestingly, in both cell types the quantal variance of AMPARs was significantly smaller than that of NMDARs, which could be attributable to differences intrinsic to or between release sites (Bekkers, 1994).

\section{Functional implications}

The firing properties of SON neurons are dependent on several $\mathrm{Ca}^{2+}$-dependent processes (for review, see Bourque and Renaud, 1990). In SON neurons, rises in cytosolic $\mathrm{Ca}^{2+}$ can occur through different mechanisms, including (1) high-voltage-gated $\mathrm{Ca}^{2+}$ channels (Fisher and Bourque, 1995; Foehring and Armstrong, 1996), (2) $\mathrm{Ca}^{2+}$ release from intracellular stores ( $\mathrm{Li}$ and Hatton, 1997), and (3) synaptically mediated $\mathrm{Ca}^{2+}$ entry. $\mathrm{Hu}$ and Bourque (1992) showed that calcium influx through NMDARs induced rhythmic bursting activity in SON neurons. In the present study we showed that $\mathrm{Ca}^{2+}$-permeable AMPARs in SON neurons provide an additional pathway for glutamate-mediated $\mathrm{Ca}^{2+}$ entry. As opposed to other mechanisms, $\mathrm{Ca}^{2+}$-permeable AMPARs allow $\mathrm{Ca}^{2+}$ entry at subthreshold membrane potentials. Thus, these alternative pathways for $\mathrm{Ca}^{2+}$ entry may function under different physiological contexts, depending on the membrane potential of the neurons. $\mathrm{Ca}^{2+}$-permeable AMPARs have been shown to be involved in several physiological functions, including strengthening of synaptic transmission (Gu et al., 1996), regulation of $\mathrm{Ca}^{2+}$-dependent $\mathrm{K}^{+}$currents (Muller et al., 1992), inhibition of high-voltage-activated $\mathrm{Ca}^{2+}$ currents (Zeilhofer et al., 1993), and inactivation of NMDA receptors (Burnashev, 1996).

Our results suggest that OT and VP neurons express functionally different AMPARs, which may contribute to the expression of distinct firing patterns. It was shown recently that the expression of NMDAR subunits in SON neurons is affected during dehydration (Meeker et al., 1994; Decavel and Curras, 1997). It would also be important to establish whether the expression of GLURs is also dynamically controlled by reproductive states, such as shown for $\mathrm{GABA}_{\mathrm{A}}$ receptors during parturition (Brussaard et al., 1997).

\section{REFERENCES}

Al-Ghoul WM, Meeker RB, Greenwood RS (1997) Differential expression of five $N$-methyl-D-aspartate receptor subunit mRNAs in vasopressin and oxytocin neuroendocrine cells. Brain Res Mol Brain Res 44:262-272.

Angulo MC, Lambolez B, Audinat E, Hestrin S, Rossier J (1997) Subunit composition, kinetic, and permeation properties of AMPA receptors in single neocortical nonpyramidal cells. J Neurosci 17:6685-6696.

Armstrong WE (1995) Morphological and electrophysiological classification of hypothalamic supraoptic neurons. Prog Neurobiol 47:291-339.

Bekkers J (1994) Quantal analysis of synaptic transmission in the central nervous system. Curr Opin Neurobiol 4:360-365.

Bekkers JM, Stevens CF (1989) NMDA and non-NMDA receptors are co-localized at individual excitatory synapses in cultured rat hippocampus. Nature 341:230-233.

Bourque CW (1988) Transient calcium-dependent potassium current in 
magnocellular neurosecretory cells of the rat supraoptic nucleus. J Physiol (Lond) 397:331-347.

Bourque CW, Renaud LP (1990) Electrophysiology of mammalian magnocellular vasopressin and oxytocin neurosecretory neurons. Front Neuroendocrinol 11:183-212.

Brussaard A, Kits K, Baker R, Willems W, Leyting-Vemeulen J, Voorn P, Smit A, Bicknell R, Herbison A (1997) Plasticity in fast synaptic inhibition of adult oxytocin neurons caused by switch in GABA-A receptor subunit expression. Neuron 19:1103-1114.

Burnashev N (1996) Calcium permeability of glutamate-gated channels in the central nervous system. Curr Opin Neurobiol 6:311-317.

Decavel C, Curras MC (1997) Increased expression of the $N$-methyl-Daspartate receptor subunit, NR1, in immunohistochemically identified magnocellular hypothalamic neurons during dehydration. Neuroscience 78:191-202.

Fisher TE, Bourque CW (1995) Voltage-gated calcium currents in the magnocellular neurosecretory cells of rat supraoptic nucleus. J Physiol (Lond) 486:571-580.

Foehring R, Armstrong WE (1996) Pharmacological dissection of high voltage-activated $\mathrm{Ca} 2+$ current types in acutely-dissociated rat supraoptic magnocellular neurons. J Neurophysiol 76:977-983.

Geiger JR, Melcher T, Koh DS, Sakmann B, Seeburg PH, Jonas P, Monyer H (1995) Relative abundance of subunit mRNAs determines gating and $\mathrm{Ca} 2+$ permeability of AMPA receptors in principal neurons and interneurons in rat CNS. Neuron 15:193-204.

Gribkoff VK (1991) Electrophysiological evidence for $N$-methyl-Daspartate excitatory amino acid receptors in the rat supraoptic nucleus in vitro. Neurosci Lett 131:260-262.

Gribkoff VK, Dudek FE (1990) Effects of excitatory amino acid antagonists on synaptic responses of supraoptic neurons in slices of rat hypothalamus. J Neurophysiol 63:60-71.

Gu J, Albuquerque C, Lee C, MacDermott A (1996) Synaptic strengthening through activation of $\mathrm{Ca} 2+$ permeable AMPA receptors. Nature 381:793-796.

Hamill OP, Marty A, Neher E, Sakmann B, Sigworth FJ (1981) Improved patch-clamp techniques for high-resolution current recording from cells and cell-free membrane patches. Pflügers Arch 391:85-100.

Hestrin S (1992) Activation and desensitization of glutamate-activated channels mediating fast excitatory synaptic currents in the visual cortex. Neuron 9:991-999.

Hestrin S (1993) Different glutamate receptor channels mediate fast excitatory synaptic currents in inhibitory and excitatory cortical neurons. Neuron 11:1083-1091.

Hollmann M, Heinemann S (1994) Cloned glutamate receptors. Annu Rev Neurosci 17:31-108.

Horikawa K, Armstrong WE (1988) A versatile means of intracellular labeling: injection of biocytin and its detection with avidin conjugates. J Neurosci Methods 25:1-11.

$\mathrm{Hu}$ B, Bourque CW (1992) NMDA receptor-mediated rhythmic bursting activity in rat supraoptic nucleus neurons in vitro. J Physiol (Lond) 458:667-687.

Jonas P, Spruston N (1994) Mechanisms shaping glutamate-mediated excitatory postsynaptic currents in the CNS. Curr Opin Neurobiol 4:366-372.

Jones M, Westbrook G (1996) The impact of receptor desensitization on fast synaptic transmission. Trends Neurosci 19:96-101.

Lewis CA (1979) Ion-concentration dependence of the reversal potential and the single channel conductance of ion channels at the frog neuromuscular junction. J Physiol (Lond) 286:417-445.

Li Z, Hatton GI (1997) $\mathrm{Ca} 2+$ release from internal stores: role in generating depolarizing after-potentials in rat supraoptic neurones. J Physiol (Lond) 498:339-350.

McBain C, Mayer M (1994) N-methyl-D-aspartic acid receptor structure and function. Physiol Rev 74:723-760.

Meeker RB, Swanson DJ, Greenwood RS, Hayward JN (1993) Quantitative mapping of glutamate presynaptic terminals in the supraoptic nucleus and surrounding hypothalamus. Brain Res 600:112-122.
Meeker RB, McGinnis S, Greenwood RS, Hayward JN (1994) Increased hypothalamic glutamate receptors induced by water deprivation. Neuroendocrinology 60:477-485.

Moos FC, Rossi K, Richard P (1997) Activation of $N$-methyl-D-aspartate receptors regulates basal electrical activity of oxytocin and vasopressin neurons in lactating rats. Neuroscience 77:993-1002.

Muller T, Moller T, Berger T, Schnitzer J, Kettenmann H (1992) Calcium entry through kainate receptors and resulting potassium-channel blockade in bergmann glial cells. Science 256:1563-1566.

Nissen R, Hu B, Renaud LP (1994) N-methyl-D-aspartate receptor antagonist ketamine selectively attenuates spontaneous phasic activity of supraoptic vasopressin neurons in vivo. Neuroscience 115-120.

Nissen R, Hu B, Renaud LP (1995) Regulation of spontaneous phasic firing of rat supraoptic vasopressin neurones in vivo by glutamate receptors. J Physiol (Lond) 484:415-424.

Oliet SHR, Bourque CW (1992) Properties of supraoptic magnocellular neurons isolated from the adult rat. J Physiol (Lond) 455:291-306.

Parker SL, Crowley WR (1993) Stimulation of oxytocin release in the lactating rat by a central interaction of alpha 1-adrenergic and alphaamino-3-hydroxy-5-methylisoxazole-4-propionic acid-sensitive excitatory amino acid mechanisms. Endocrinology 133:2855-2860.

Poulain DA, Wakerley JB (1982) Electrophysiology of hypothalamic magnocellular neurons secreting oxytocin and vasopressin. Neuroscience 7:773-808.

Redman S (1990) Quantal analysis of synaptic potentials in neurons of the central nervous system. Physiol Rev 70:165-198.

Richardson CM, Wakerley JB (1997) Glutamate excitation of oxytocin neurones in vitro involves predominantly non-NMDA receptors. Brain Res 767:158-161.

Sigworth FJ (1980) The variance of sodium current fluctuations at the node of Ranvier. J Physiol (Lond) 307:97-129.

Silver RA, Cull-Candy SG, Takahashi T (1996) Non-NMDA glutamate receptor occupancy and open probability at a rat cerebellar synapse with single and multiple release sites. J Physiol (Lond) 494:231-250.

Smith BN, Armstrong WE (1993) Histamine enhances the depolarizing afterpotential of immunohistochemically identified vasopressin neurons in the rat supraoptic nucleus via H1-receptor activation. Neuroscience 53:855-864.

Stern JE, Armstrong WE (1997) Sustained outward rectification of oxytocinergic neurones in the rat supraoptic nucleus: ionic dependence and pharmacology. J Physiol (Lond) 500:497-508.

Stern JE, Armstrong WE (1998) Reorganization of the dendritic trees of oxytocin and vasopressin neurons of the rat supraoptic nucleus during lactation. J Neurosci 18:841-853.

Traynelis SF, Angus Silver R, Cull-Candy SG (1993) Estimated conductance of glutamate receptor channels activated during EPSCs at the cerebellar mossy fiber-granule cell synapse. Neuron 11:279-289.

van den Pol AN, Wuarin JP, Dudek FE (1990) Glutamate, the dominant excitatory transmitter in neuroendocrine regulation. Science 250:1276-1278.

Wakerley J, Lincoln D (1973) The milk-ejection reflex of the rat: a 20- to 40 -fold acceleration in the firing of paraventricular neurones during oxytocin release. J Endocrinol 57:477-493.

Wuarin JP, Dudek FE (1993) Patch-clamp analysis of spontaneous synaptic currents in supraoptic neuroendocrine cells of the rat hypothalamus. J Neurosci 13:2323-2331.

Yang C, Senatorov V, Renaud LP (1994) Organum vasculosum lamina terminalis-evoked postsynaptic responses in rat supraoptic neurons in vitro. J Physiol (Lond) 477:59-74.

Yang QZ, Smithson KG, Hatton GI (1995) NMDA and non-NMDA receptors on rat supraoptic nucleus neurons activated monosynaptically by olfactory afferents. Brain Res 680:207-216.

Zeilhofer H, Muller T, Swandulla D (1993) Inhibition of high voltageactivated calcium currents by L-glutamate receptor-mediated calcium influx. Neuron 10:879-887. 